\title{
Perancangan Aplikasi Sistem Informasi Barang Berbasis Android Pada PT. Quantum Mitra Sinergi
}

\author{
Albert Anotona Hary Saputra Gulo \\ PT. Quantum Mitra Sinergi \\ e-mail: gulo.albert92@gmail.com
}

\begin{abstract}
Abstrak
Di era teknologi sekarang ini hampir semua perusahaan memanfaatkan perkembangan teknologi untuk mengembangkan perusahaan maupun bisnis mereka. PT. Quantum Mitra Sinergi merupakan salah satu perusahaan yang bergerak dalam bidang IT yang membutuhkan suatu aplikasi yang dapat membantu pekerja dalam mencatat barang masuk dan keluar. Salah satu alat yang dapat membantu pekerja adalah perangkat mobile yang dapat menjalankan suatu aplikasi sistem inventaris untuk perusahaan. Dalam hal ini aplikasi tersebut diharapkan dapat menolong pekerja dalam mencatat data barang keluar dan masuk dari dan ke dalam gudang penyimpanan perusahaan. Metode yang dipakai dalam penelitian ini ialah metode waterfal/ dimulai dari analisa kebutuhan, desain sistem, implementasi, verifikasi dan pemeliharaan. Tujuan dari penelitian ini adalah untuk membantu pekerja mengelola data barang dengan baik melalui sistem aplikasi yang akan dibangun. Penelitian ini menghasilkan aplikasi sistem inventaris pada PT. Quantum Mitra Sinergi yang dapat digunakan pada smartphone Android. Dengan adanya fitur scan barcode menggunakan kamera smartphone, pekerja dapat mendata barang yang hendak masuk maupun keluar dari tempat penyimpanan barang dengan lebih fleksibel dan lebih cepat, perancangan sistem dibangun dengan dua sistem yang berbeda yaitu Android dan juga Web.
\end{abstract}

Kata kunci: Sistem informasi barang, Smartphone, Android, Web

\section{PT. QUANTUM MITRA SINERGI Design of Goods Inventory System at PT. Quantum Mitra Sinergi based on Android}

\begin{abstract}
In today's technological era, almost all companies take advantage of technological developments to develop their companies and businesses. PT. Quantum Mitra Sinergi is a company engaged in the IT field that requires an application that can assist workers in recording incoming and outgoing goods. One of the tools that can help workers is a mobile device that can run an inventory system application for the company. In this case, the application is expected to be able to help workers in recording data on goods going out and going to and from the company's warehouse. The method used in this research is the waterfall method starting from requirements analysis, system design, implementation, verification and maintenance. The purpose of this study is to help workers manage data goods properly through the application system to be built. This study produces an inventory system application at PT. Quantum Mitra Sinergi which can be used on Android smartphones. With the barcode scanning feature using a smartphone camera, workers can record items that want to enter and leave the goods storage area more flexibly and quickly, the system design is built with two different systems, namely Android and also the Web.
\end{abstract}

Keywords: Goods Inventory System, Barcode Scan, Smartphone, Android, Web 


\section{Pendahuluan}

Pada zaman sekarang ini, teknologi telah menjadi salah satu kebutuhan utama manusia. Dengan adanya teknologi ini, pekerjaan manusia menjadi lebih cepat dan efisien. Seiring berjalannya waktu, teknologi juga semakin berkembang. Perkembangan teknologi ini juga diarahkan ke arah yang diinginkan dan dibutuhkan manusia. Teknologi telah dipakai dalam berbagai macam bidang. Ada dalam bidang pendidikan, ke pemerintahan, kesehatan, hiburan, dan bahkan dalam perusahaan maupun bisnis. Dalam bidang perusahaan maupun bisnis, smartphone pada umumnya masyarakat menggunakan teknologi untuk mempercepat pekerjaan karena smartphone memiliki tingkat mobilitas yang lebih baik dibandingkan PC maupun laptop.

PT. Quantum Mitra Sinergi adalah sebuah perusahaan yang bergerak dalam bidang penyediaan barang teknologi informasi di Indonesia. Sebelumnya perusahaan tersebut mendaftarkan barang-barang di gudang penyimpanan dengan mengetikkan serial number ke dalam komputer melalui aplikasi Excel. Waktu yang dibutuhkan tentunya semakin banyak karena barang yang didaftarkan juga tidak sedikit dan sering terjadi salah pengetikan yang menyebabkan nama-nama barang menjadi salah. Komputer (PC) maupun laptop juga berukuran lebih besar dibandingkan dengan smartphone sehingga sulit untuk dibawa yang menyebabkan berkurangnya tingkat mobilitas jika diperlukan. Oleh karena itu dibutuhkan sebuah solusi yang dapat memudahkan karyawan PT. Quantum Mitra Sinergi dalam administrasi barang masuk dan keluar yang dapat memberikan laporan barang kepada pihak kepala pergudangan?

Di dalam penelitian ini penulis merancang sebuah aplikasi yang dapat mendata stok barang menggunakan smartphone dengan harapan smartphone dapat memberikan mobilitas yang tinggi dan mempercepat pekerjaan. Dengan latar belakang di atas, penulis akan melakukan penelitian dengan perancangan aplikasi Android untuk mempermudah dan mempercepat pekerjaan di gudang penyimpanan barang pada PT. Quantum Mitra Sinergi.

\section{Tinjauan Pustaka}

\section{Sistem informasi}

Sistem informasi adalah suatu sistem di dalam suatu organisasi yang mempertemukan kebutuhan pengelolaan transaksi harian, mendukung operasi, bersifat manajerial, dan kegiatan strategi dari suatu organisasi dan menyediakan pihak luar tertentu dengan laporan-laporan yang dibutuhkan.[1]

\section{Basis Data}

Basis data terdiri dari dua suku kata, yaitu data dan basis. Data dapat diartikan sebagai representasi fakta dunia nyata yang mewakili suatu objek, misalnya manusia, hewan, barang, peristiwa, konsep, dan lain sebagainya yang direkam dalam bentuk huruf, teks, simbol, angka, suara, gambar dan lainnya. Basis juga dapat di artikan sebagai kumpulan file, tabel, arsip yang saling berhubungan yang disimpan di dalam media elektronis [2].

\section{Website}

Website adalah suatu sistem yang berkaitan dengan dokumen digunakan sebagai media untuk menampilkan teks, gambar, multimedia dan lainnya pada jaringan internet [3]. Dengan adanya perkembangan Internet yang sangat pesat, penggunaan aplikasi berbasis website menjadi sesuatu yang umum, karena dapat diimplementasikan tanpa perlu melakukan instalasi aplikasi di komputer client. Dalam perancangan ini aplikasi web digunakan sebagai bagian administrasi untuk mempermudah administrasi barang dan pengguna.

\section{Aplikasi Mobile}

Perkembangan smartphone didukung dengan tersedianya sistem operasi mobile yang dapat menjalankan aplikasi sesuai dengan kebutuhan dari penggunanya. Ada dua sistem operasi mobile yang 
popular sekarang ini yaitu iOS yang dikembangkan oleh Apple dan Android yang dikembangkan oleh Google. Sistem operasi yang modern ini memungkinkan pengembangan aplikasi yang dapat berjalan di atasnya menjadikan aplikasi mobile sebagai sarana utama yang digunakan oleh masyarakat untuk mengakses layanan berbasis Internet.

\section{Penelitian Berkaitan}

Penelitian mengenai sistem informasi barang merupakan hal yang telah menarik para peneliti, yang menghasilkan hasil penelitian yang berkaitan dengan perancangan yang dilakukan ini. Pada penelitian yang dilakukan oleh [4-5], pada saat proses pengolahan persediaan barang dijalankan dengan sebuah perangkat lunak, maka proses dapat dilakukan lebih baik dengan cepat dan akurat. Namun demikian, penelitian terdahulu, belum mengakomodir penggunaan smartphone untuk mempermudah pengoperasian sistem informasi barang.

\section{Analisa dan Perancangan Sistem}

\section{Metode penelitian}

Metode yang digunakan penulis untuk penelitian perancangan sistem adalah metodologi yang umum digunakan yaitu: SDLC (System Development Life Cycle) Waterfall [6] yang digunakan ini terbagi menjadi beberapa bagian sebagai berikut:

1. Analisa Kebutuhan

Pada tahapan ini penulis akan menganalisa permasalahan dan kebutuhan yang diperlukan untuk perancangan sistem. Sistem hanya akan digunakan oleh Administrator dan User yang bekerja di bagian inventaris, maka masukan hanya berasal dari mereka mulai dari fitur yang akan dibangun hingga data yang akan dimasukkan ke dalam sistem yang akan dibangun.

2. Desain Sistem

Pada tahapan ini yang akan dilakukan adalah mendesain sistem dengan menggunakan User Case Diagram, Activity Diagram, Sequence Diagram, Class Diagram dan tahap desain tampilan.

3. Coding

Pada tahapan ini penulis menggunakan kode pemrograman untuk menerjemahkan rencana dan analisis sistem ke dalam bahasa pemrograman tertentu yang dimengerti oleh komputer. Kode yang dibentuk akan menghasilkan suatu sistem informasi yang sesuai dengan perintah perancangan.

4. Pengujian

Sistem yang sudah dibangun akan dilakukan pengujian, apakah sistem sudah sesuai dengan kriteria yang dimaksud oleh pihak inventaris.

5. Perawatan (maintenance)

Kegiatan perawatan merupakan kegiatan pemeliharaan yang dilakukan agar sistem tetap berjalan sesuai dengan tujuan pembuatan dan dapat digunakan untuk waktu yang lama.

\section{Latar Belakang Objek Penelitian}

PT Quantum Mitra Sinergi adalah sebuah perusahaan IT yang dimulai pada bulan Desember tahun 2009. Perusahaan ini memiliki Tagline "The Value Added Services and Total Solutions"yang memiliki arti " Layanan Nilai Tambah dan Solusi Total". Perusahaan ini didukung oleh para profesional muda yang mempunyai integritas dan kemampuan dalam mengembangkan teknologi informasi di Indonesia.

PT Quantum Mitra Sinergi ini juga adalah sebuah perusahaan dagang untuk peralatan dan sistem keselamatan dan pengemudi elektronik, contohnya adalah Driver Fatigue Monitor MR688 CareDriver, sistem kamera kendaraan berat ORLACO, Sistem AVL Advance \& banyak lagi. 


\section{Use Case Diagram}

Dalam sistem ini terdapat pengguna yaitu User yang menjadi pengguna aplikasi web maupun Android dan seorang user sebagai pengguna Android. Berikut adalah gambar dari use case diagram web dan Android yaitu sebagai berikut:

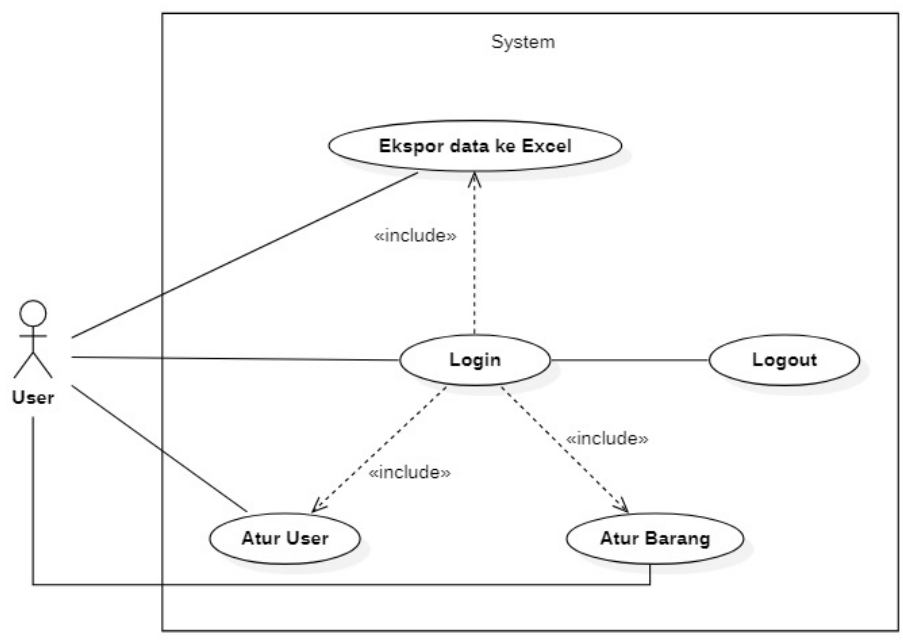

Gambar 1 Use Case Diagram

Di dalam Gambar 1, terdapat aktor yang, dapat login untuk masuk ke dalam sistem dan logout untuk keluar dari dalam sistem, melihat data barang, laporan barang keluar, dan semua barang yang masuk., dapat melakukan input, edit, hapus barang, dan ekspor data ke Excel.

\begin{tabular}{|c|c|c|}
\hline \multirow[b]{2}{*}{ User } & Barang & \\
\hline & \multirow{7}{*}{$\begin{array}{l}\text { +id_barang } \\
\text { +nomor_serial } \\
\text { +imei } \\
\text { +id_tipe_barang } \\
\text { +nama } \\
\text { +tanggal_masuk } \\
\text { +tanggal_keluar } \\
\text { +id_user_masuk } \\
\text { +id_user_keluar } \\
\text { +foto }\end{array}$} & \\
\hline \multirow{5}{*}{$\begin{array}{l}\text { +id_user } \\
\text { +nama_user } \\
\text { +alamat } \\
\text { +email } \\
\text { +no_hp } \\
\text { +username } \\
\text { +password } \\
\text { +hak_akses }\end{array}$} & & \\
\hline & & Tipe_barang \\
\hline & & +id tipe barang \\
\hline & & +tipe_barang \\
\hline & & +tambah_tipe() \\
\hline \multirow{5}{*}{$\begin{array}{l}\text { +tambah_barang() } \\
\text { +hapus() } \\
\text { +update_barang() } \\
\text { +tambah_user() }\end{array}$} & & +update() \\
\hline & \multirow{4}{*}{$\begin{array}{l}\text { +tambah_barang() } \\
\text { +catat_barang_masuk() } \\
\text { +catat_barang_keluar() } \\
\text { + hapus_barang() } \\
\text { +update() }\end{array}$} & \\
\hline & & \\
\hline & & \\
\hline & & \\
\hline
\end{tabular}

Gambar 2 Class Diagram

\section{Class Diagram}

Class Diagram adalah salah satu jenis diagram pada Unified Modeling Language (UML)yang digunakan untuk menampilkan kelas-kelas maupun paket-paket yang ada pada suatu sistem yang nantinya akan digunakan . Jadi diagram ini dapat memberikan sebuah gambaran mengenai sistem maupun relasi-relasi yang terdapat pada sistem tersebut. Gambar 2 merupakan tampilan class diagram. Pada class diagram ini memiliki 3 (tiga) tabel atau entitas yang memiliki hubungan masing-masing. 
Perancangan Aplikasi Sistem Informasi Barang Berbasis Android Pada PT. Quantum Mitra Sinergi

\section{Perancangan Antar Muka Aplikasi Web}

Rancangan desain sistem dibuat bertujuan sebagai acuan dalam perancangan sebuah sistem. Berikut desain sistem yang akan direncanakan: Pada Gambar 3 dapat dilihat rancangan antar muka untuk halaman login dan halaman home awal ketika login berhasil dilakukan. Pada Gambar 4 dapat dilihat rancangan antar muka untuk menampilkan, menambahkan daftar barang baru, dan juga menghapus daftar barang dari basis data. Pada Gambar 5 dapat dilihat rancangan antar muka untuk menampilkan, dan juga menambahkan pekerja baru.

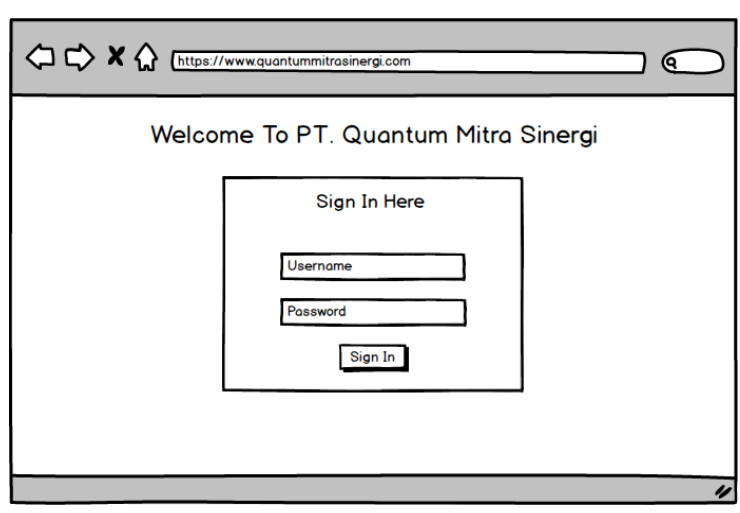

(a)

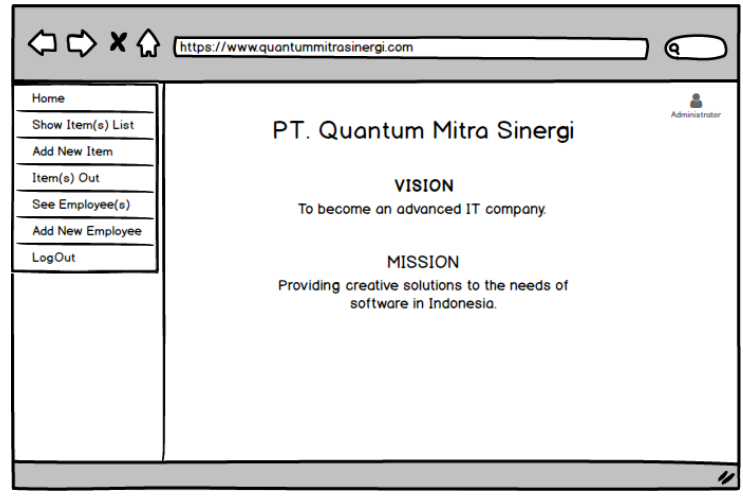

(b)

Gambar 3 Rancangan tampilan website (a) Halaman Login (b) Halaman Home

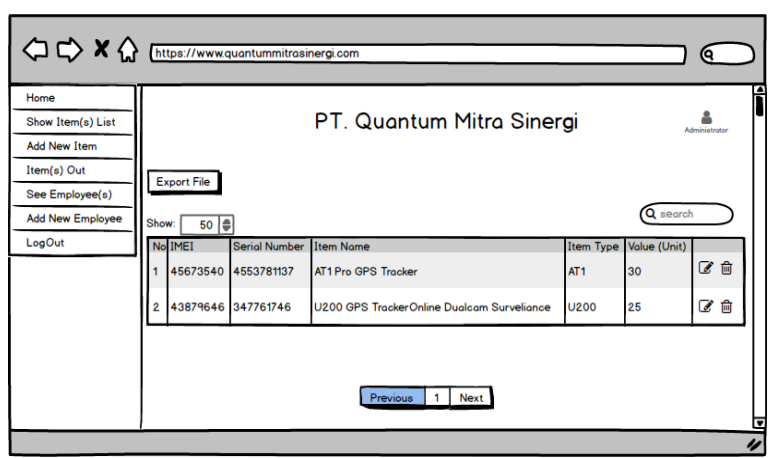

(a)

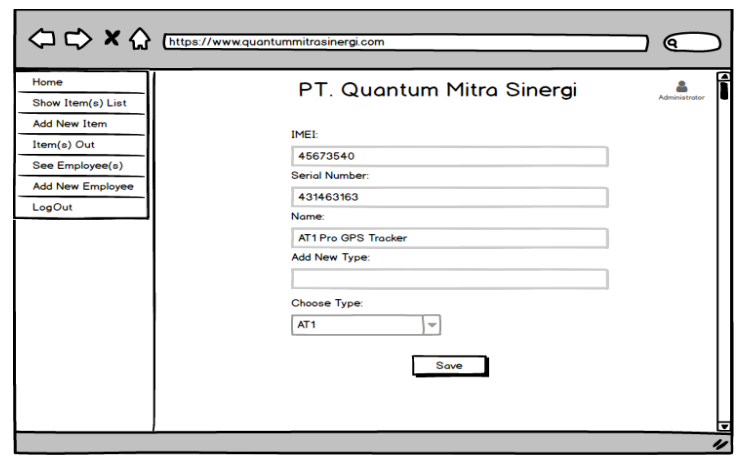

(b)

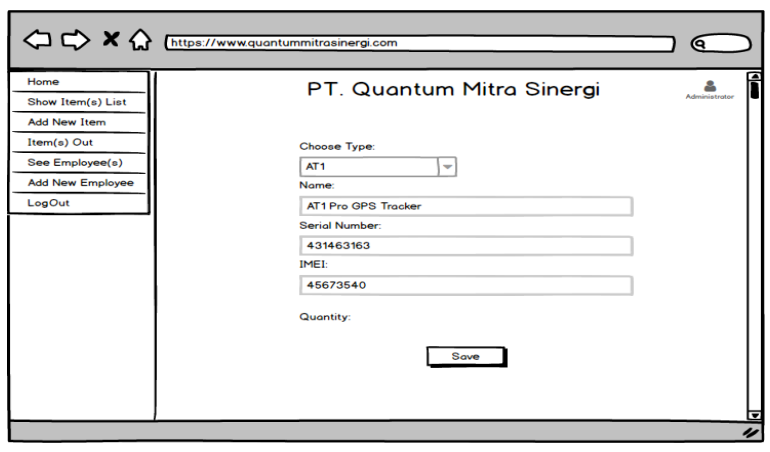

(c)

Gambar 4 Rancangan Tampilan website (a) Item List (b) Add New Item (c) Item Out 


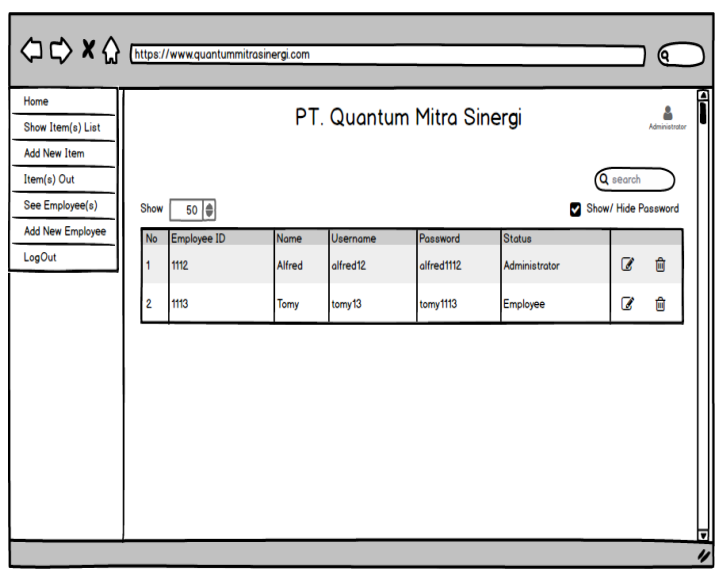

(a)

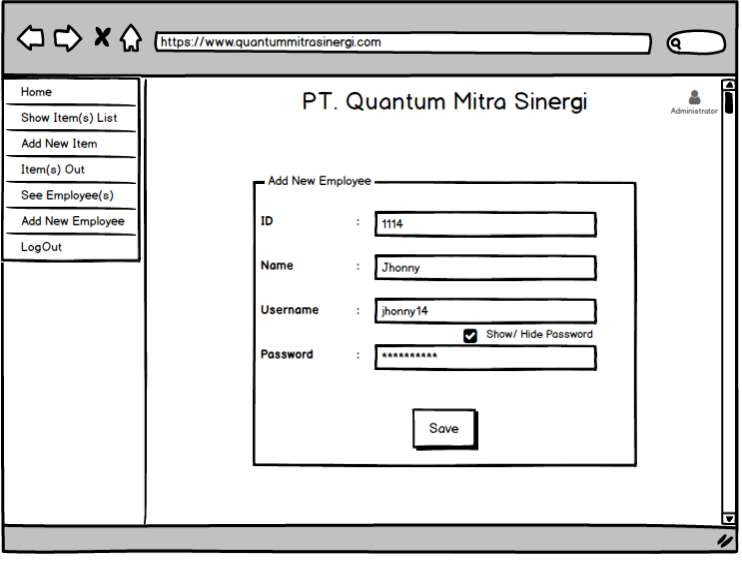

(b)

Gambar 5 Rancangan Tampilan website (a) See Employee (b) Add New Employee

\section{Perancangan Antar Muka Aplikasi Mobile}

Pada Gambar 6 merupakan rancangan tampilan Login dan rancangan tampilan Home ketika sudah berhasil melakukan Login. Pada Gambar 7 dapat dilihat rancangan antar muka untuk menambahkan tipe barang dan maupun barang baru ke dalam basis data. Pada Gambar 8 merupakan rancangan tampilan untuk menampilkan daftar barang yang telah ditambahkan ke dalam basis data, kemudian juga merupakan rancangan tampilan proses pencatatan dalam mengeluarkan barang yang telah tersimpan di dalam basis data.

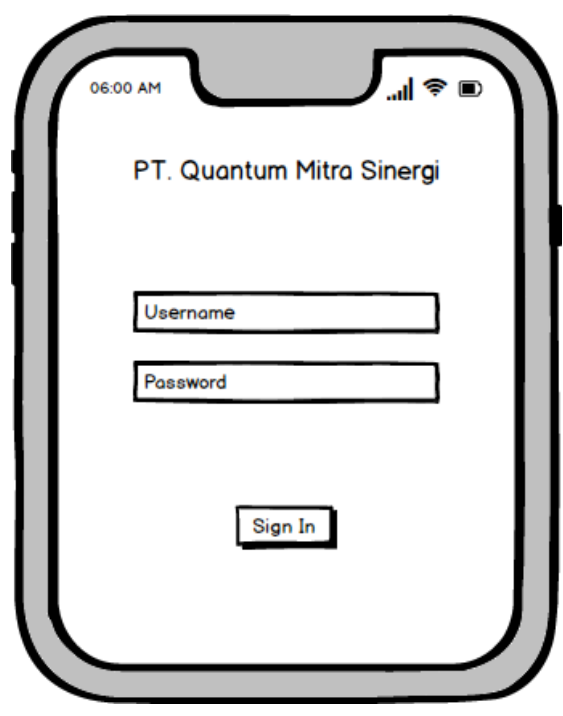

(a)

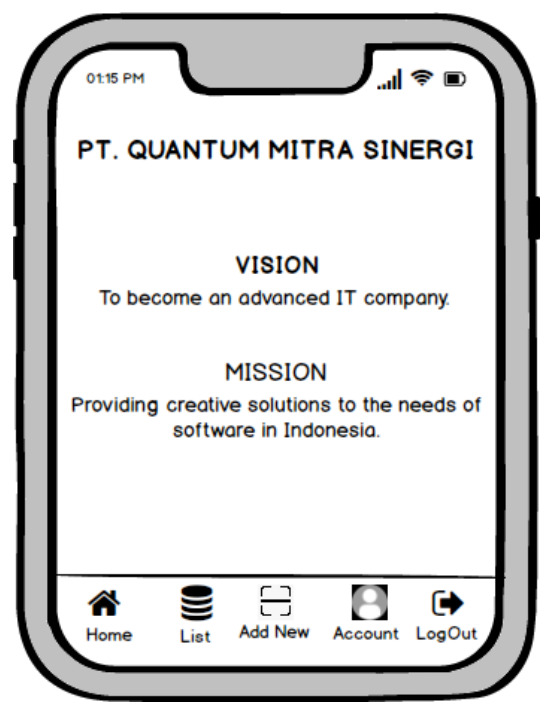

(b)

Gambar 6 Rancangan Tampilan Aplikasi Mobile (a) Tampilan Login (b) Tampilan Home 


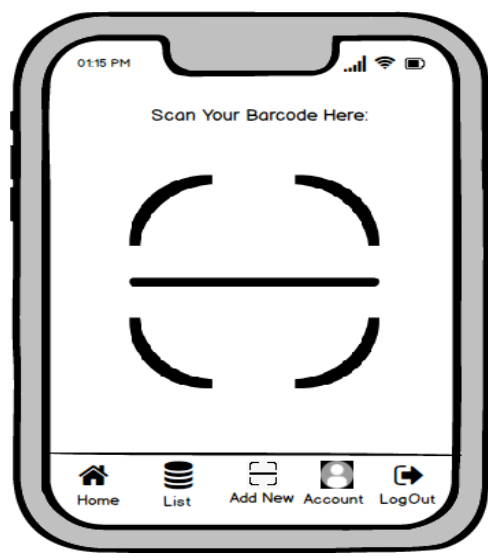

(a)

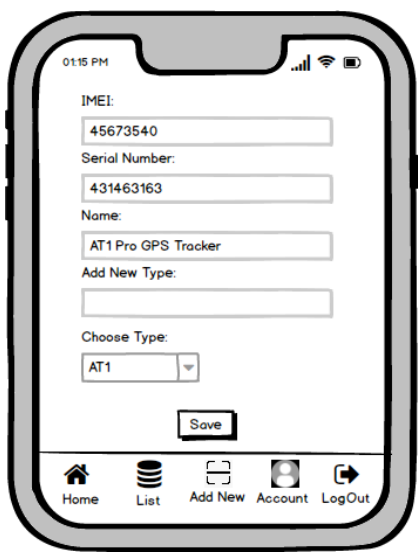

(b)

Gambar 7 Rancangan Tampilan Aplikasi Mobile (a) \& (b) Tampilan Add New Barang

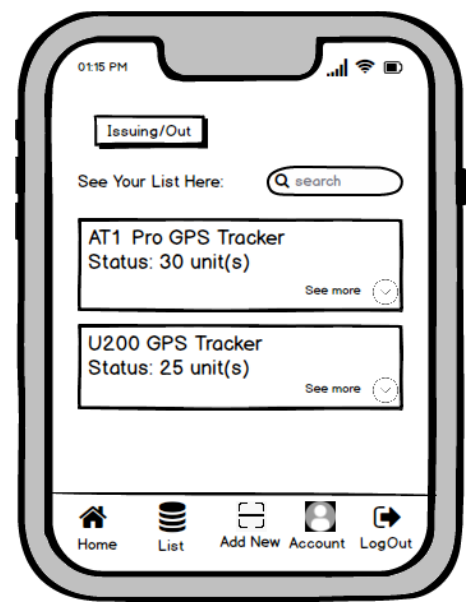

(a)

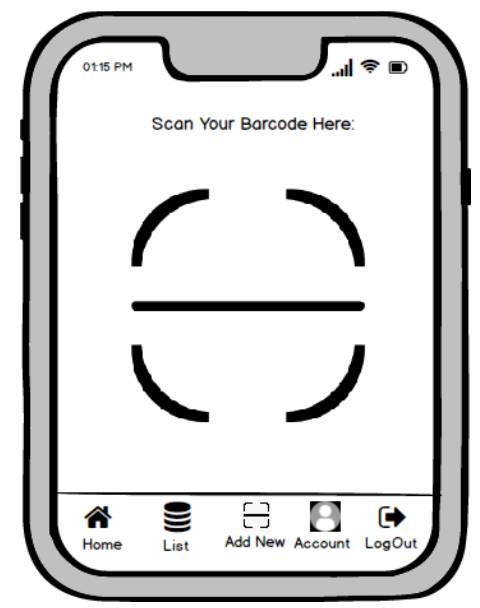

(b)

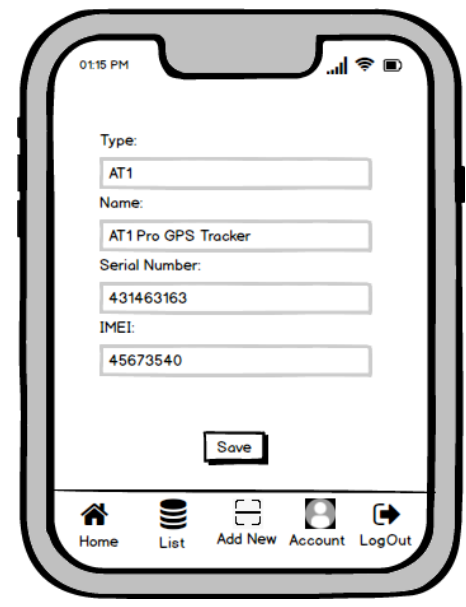

(c)

Gambar 8 Rancangan Tampilan Aplikasi Mobile (a) Tampilan List barang (b) \& (c) Tampilan Issuing/Out Barang Keluar 


\section{Hasil dan Pembahasan}

Perangkat lunak yang digunakan untuk membangun sistem informasi perancangan inventaris penyimpanan daftar barang terdiri dari beberapa komponen program. Komponen-komponen tersebut membantu agar penyimpanan data dapat berjalan dengan baik. Adapun komponen-komponen tersebut antara lain: Sistem Operasi Windows 10, Android 9, Firebase, Visual Studio Code, Google Chrome, ReactJS, React Native.

\section{Hasil Perancangan}

Rancangan yang telah dijabarkan pada bagian sebelumnya telah dituangkan dalam bentuk aplikasi web dan mobile. Karena keterbatasan tempat, maka tidak semua bagian dari aplikasi yang sudah berjalan dapat ditampilkan ditulisan ini.

\section{Aplikasi Web}

Gambar 9 menampilkan hasil dari rancangan halaman login dan tampilan halaman home aplikasi website. Admin harus memasukkan username dan password yang telah dibuat sebelumnya untuk dapat menggunakan aplikasi.

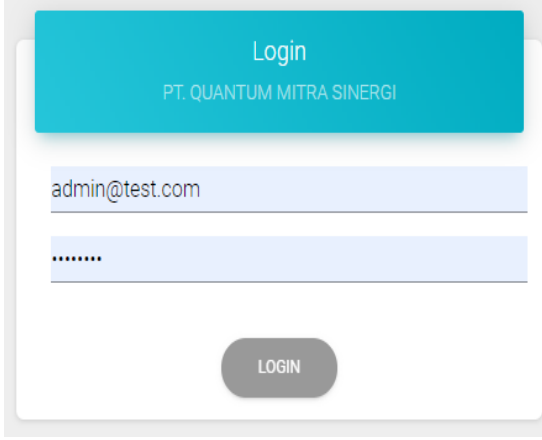

(a)

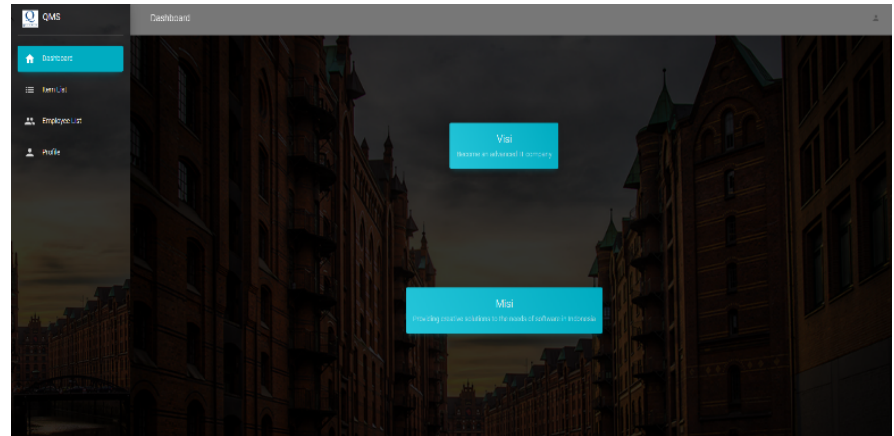

(b)

Gambar 9 Hasil rancangan website (a) Halaman Login (b) Halaman Home

Pada Gambar 10-12 menampilkan hasil akhir dari website yang dirancang. Dapat dilihat tampilan halaman untuk Item List, popup dialog Add New Type, dan popup dialog Add New Item. Website yang dihasilkan merupakan hasil penuangan rancangan yang sudah diberikan di bagian sebelumnya dari tulisan ini.

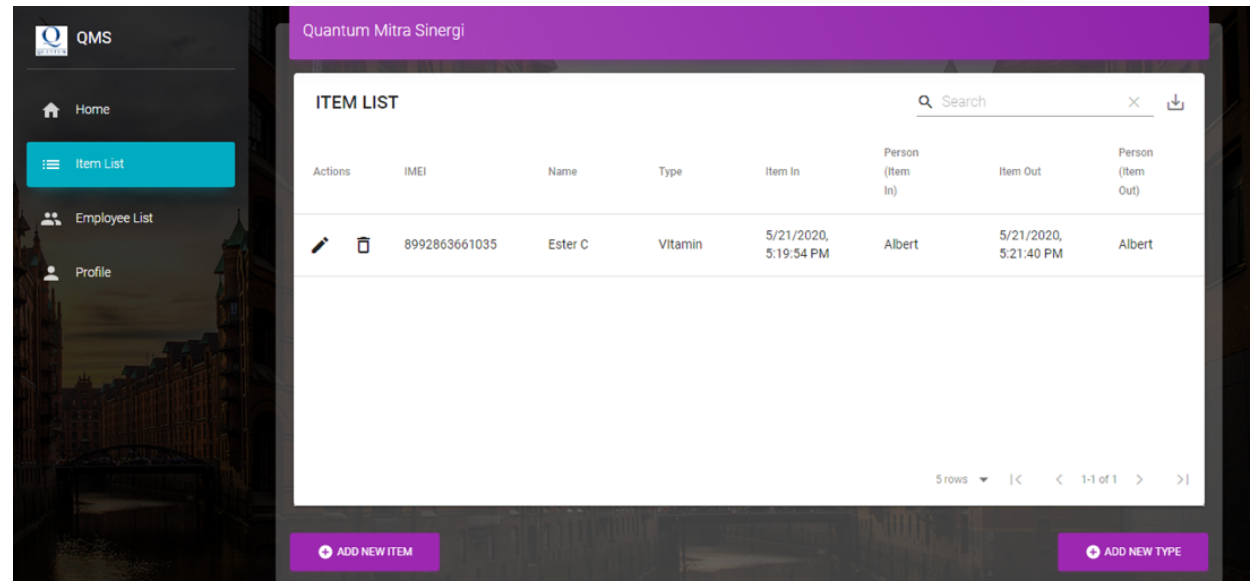

Gambar 10 Tampilan halaman Item List 


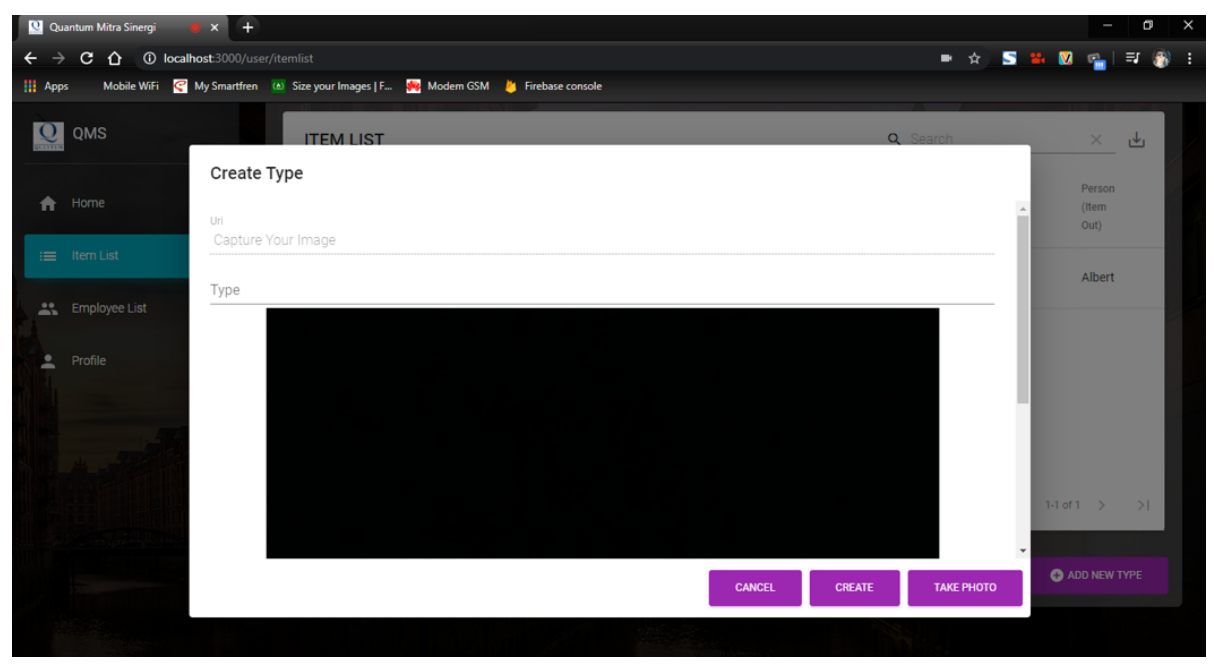

Gambar 11 Tampilan popup dialog Add New Type

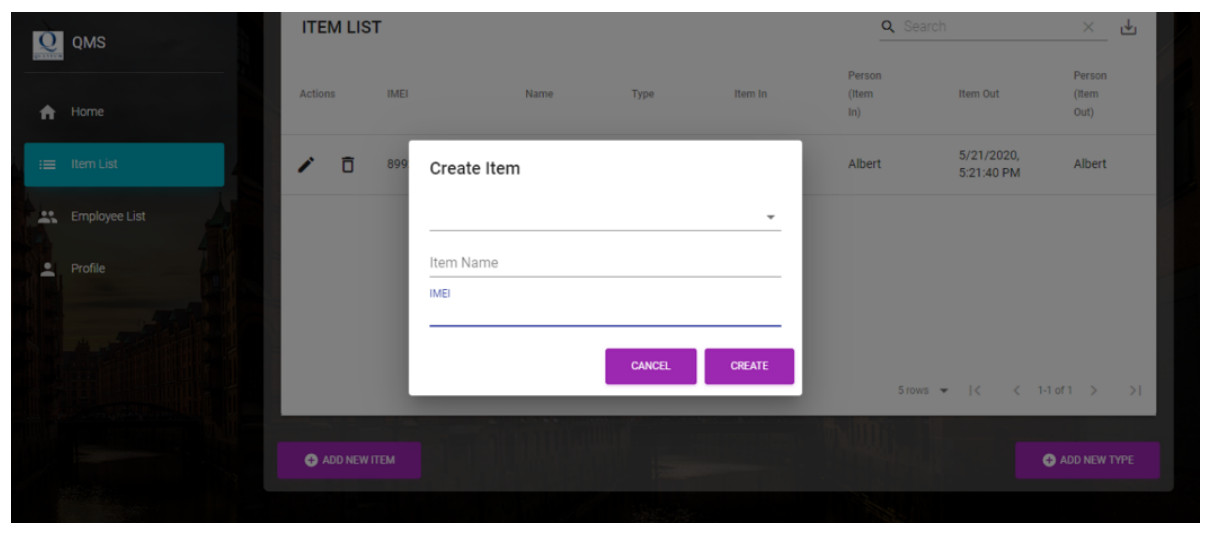

Gambar 12 Tampilan popup dialog Add New Item

Pada Gambar 13 dan 14 ditampilkan hasil akhir dari halaman Employee List dan popup dialog Add New Employee.

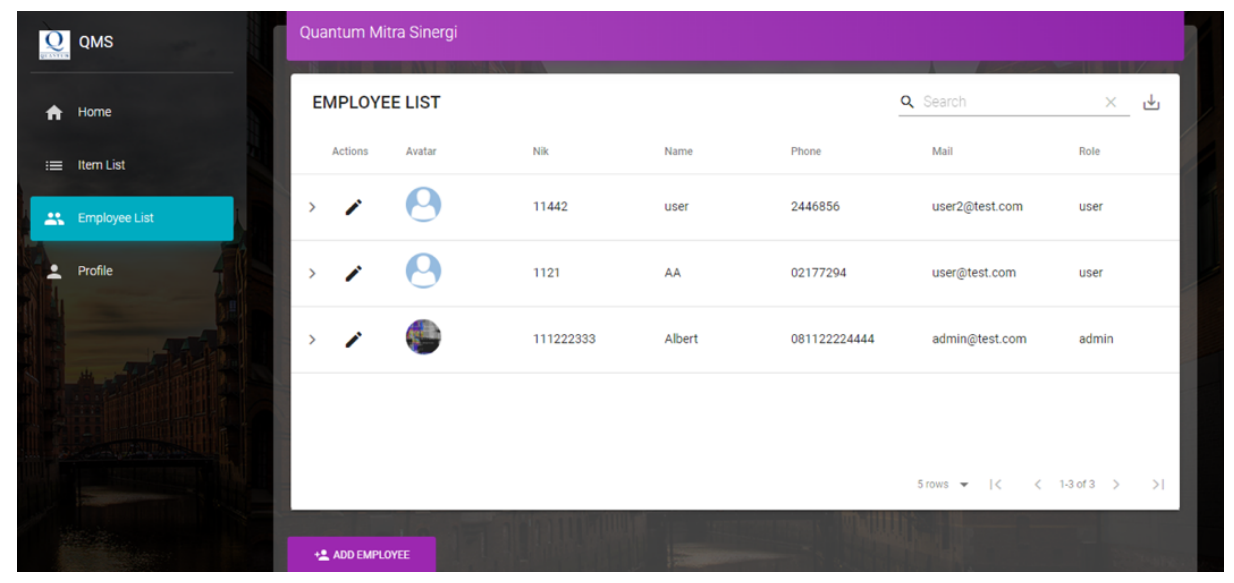

Gambar 13 Tampilan halaman Employee List 


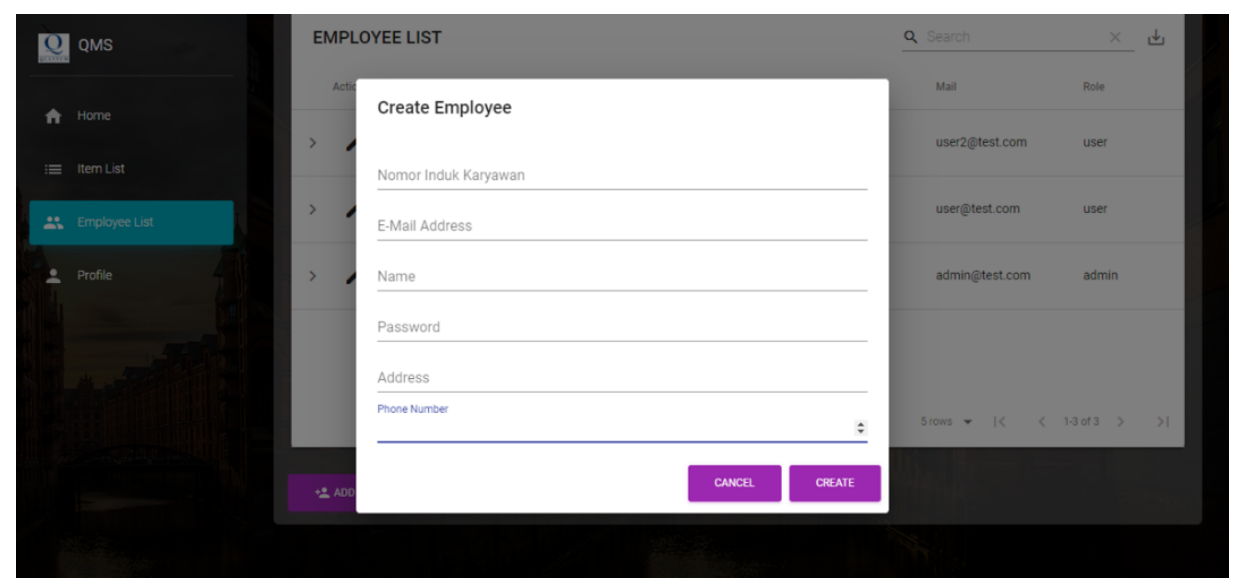

Gambar 14 Tampilan popup dialog Add New Employee

\section{Aplikasi Mobile}

Gambar 15 menampilkan hasil rancangan halaman login dan tampilan halaman home pada aplikasi mobile ketika proses login berhasil.

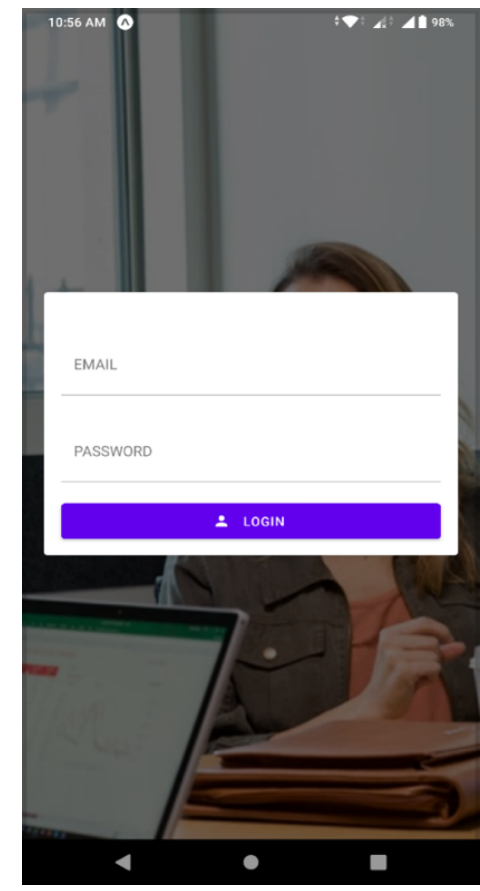

(a)

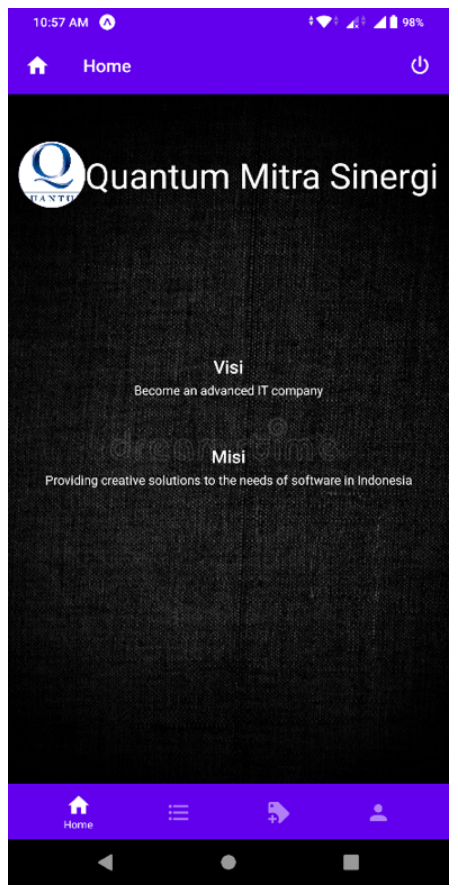

(b)

Gambar 15 Hasil rancangan aplikasi mobile (a) Halaman login (b) Halaman home

Pada Gambar 16 (a) menampilkan halaman Item List dan berisi informasi mengenai daftar barang yang telah dimasukkan ke dalam basis data inventaris berupa nama barang, jumlah barang, dan IMEI, kemudian pada popup dialog (b) merupakan tampilan pada saat barang yang terdaftar di dalam basis data ingin dikeluarkan. 
Perancangan Aplikasi Sistem Informasi Barang Berbasis Android Pada PT. Quantum Mitra Sinergi

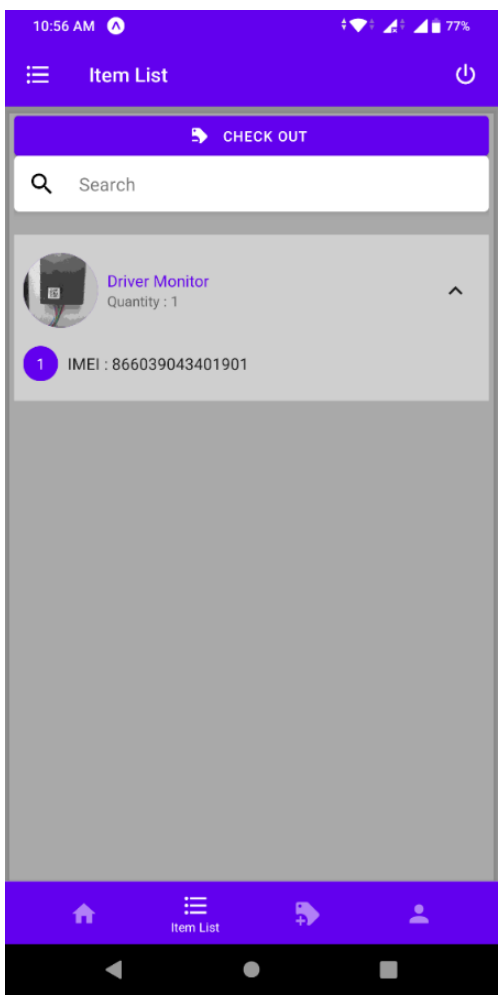

(a)

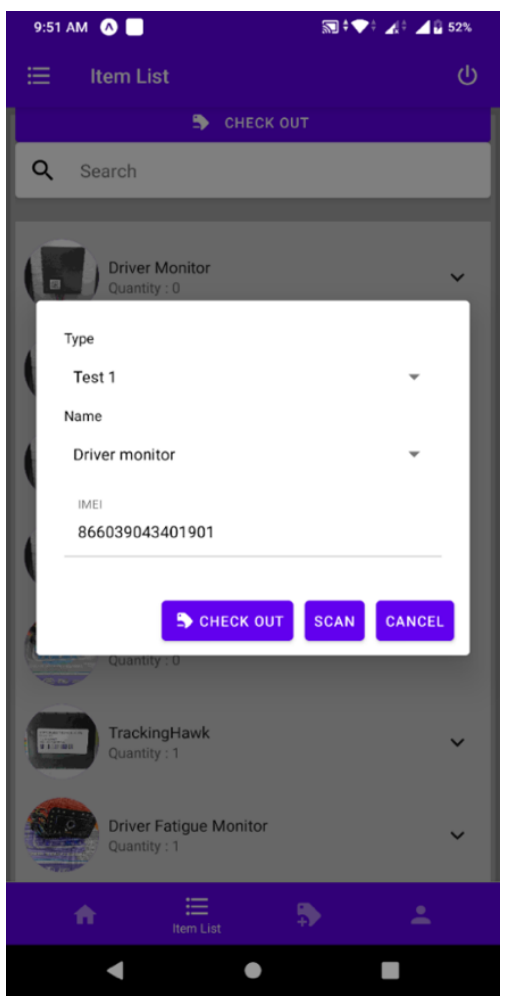

(b)

Gambar 16 Tampilan hasil rancangan aplikasi mobile (a) Halaman Item List (b) popup dialog Check Out barang

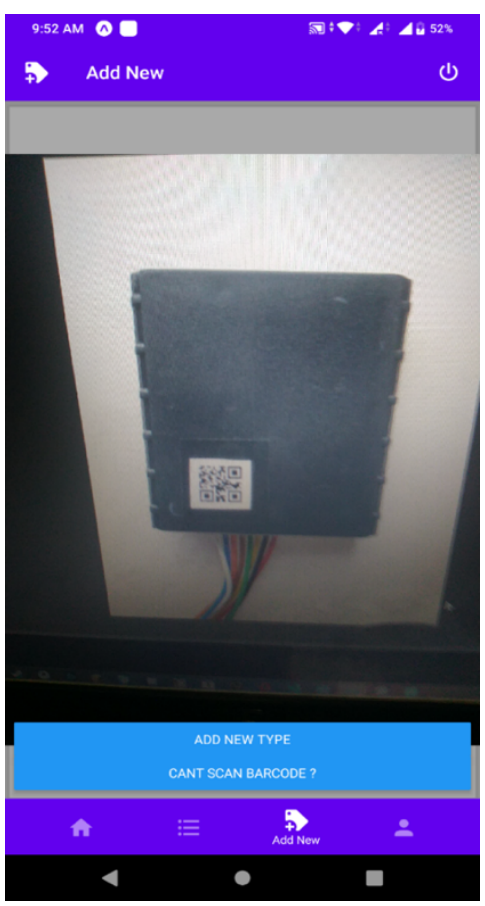

Gambar 17 Halaman Add New Barang 
Pada Gambar 17 menampilkan halaman Add New yang berfungsi untuk menambahkan barang baru dengan fitur scan barcode barang yang hendak dimasukkan ke dalam basis data menggunakan kamera smartphone itu sendiri.

\section{Pengujian Sistem}

Pada tahap pengujian ini penulis menggunakan metode Black Box. Pengujian Black Boxialah pengujian terhadap suatu program untuk mengetahui program tersebut. Hasil pengujian pada website dan aplikasi mobile terdapat di dalam Tabel 1 dan Tabel 2. Hasil pengujian yang dilakukan mendapatkan hasil yang baik dan dapat diterima untuk setiap jenis uji. Dengan demikian aplikasi yang dikembangkan dapat digunakan sesuai dengan tujuan pembuatan aplikasi.

Tabel 1 Hasil Pengujian pada website

\begin{tabular}{|c|c|c|c|c|}
\hline No. & Form yang diuji & Skenario Uji & Hasil Pengujian & Jenis Pengujian \\
\hline \multirow{2}{*}{1.} & \multirow{2}{*}{ Login } & $\begin{array}{l}\text { Masukkan } \\
\text { username dan } \\
\text { password yang } \\
\text { benar }\end{array}$ & $\begin{array}{l}\text { Proses login } \\
\text { berhasil dan masuk } \\
\text { ke halaman home }\end{array}$ & $\begin{array}{l}{[\sqrt{ } \text { ]diterima }} \\
{[\text { ]ditolak }}\end{array}$ \\
\hline & & $\begin{array}{l}\text { Masukkan } \\
\text { username dan } \\
\text { password yang } \\
\text { salah }\end{array}$ & Proses login gagal & $\begin{array}{l}{[\sqrt{ }] \text { diterima }} \\
{[\text { ]ditolak }}\end{array}$ \\
\hline \multirow{6}{*}{2.} & \multirow{6}{*}{ Item List } & $\begin{array}{l}\text { Cari daftar } \\
\text { barang }\end{array}$ & $\begin{array}{l}\text { Sistem akan } \\
\text { menampilkan daftar } \\
\text { barang yang dicari }\end{array}$ & $\begin{array}{l}{[\sqrt{ } \text { ]diterima }} \\
{[\text { ]ditolak }}\end{array}$ \\
\hline & & $\begin{array}{l}\text { Ekspor data } \\
\text { barang ke Excel }\end{array}$ & $\begin{array}{l}\text { Sistem } \\
\text { mengkonversi data } \\
\text { barang yang ada di } \\
\text { dalam basis data ke } \\
\text { dalam format Excel }\end{array}$ & $\begin{array}{l}{[\sqrt{ }] \text { diterima }} \\
{[\text { ]ditolak }}\end{array}$ \\
\hline & & $\begin{array}{l}\text { Mengubah data } \\
\text { barang }\end{array}$ & $\begin{array}{l}\text { Mengubah data } \\
\text { barang yang sudah } \\
\text { tersimpan di dalam } \\
\text { basis data }\end{array}$ & $\begin{array}{l}{[\sqrt{ } \text { ]diterima }} \\
{[\text { ]ditolak }}\end{array}$ \\
\hline & & $\begin{array}{l}\text { Menghapus } \\
\text { daftar barang }\end{array}$ & $\begin{array}{l}\text { Menghapus barang } \\
\text { yang sudah } \\
\text { tersimpan di dalam } \\
\text { basis data }\end{array}$ & $\begin{array}{l}{[\sqrt{ } \text { ]diterima }} \\
{[\text { ]ditolak }}\end{array}$ \\
\hline & & $\begin{array}{l}\text { Menambahkan } \\
\text { tipe barang baru }\end{array}$ & $\begin{array}{l}\text { Barcode barang di } \\
\text { scan lalu tipe } \\
\text { barang di ketik } \\
\text { secara manual dan } \\
\text { gambar barang di } \\
\text { foto dan } \\
\text { dimasukkan secara } \\
\text { manual }\end{array}$ & $\begin{array}{l}{[\sqrt{ }] \text { diterima }} \\
{[\text { ]ditolak }}\end{array}$ \\
\hline & & $\begin{array}{l}\text { Menambahkan } \\
\text { daftar barang } \\
\text { baru }\end{array}$ & $\begin{array}{l}\text { Barang dengan tipe } \\
\text { yang telah } \\
\text { tersimpan di dalam } \\
\text { basis data di scan } \\
\text { kemudian ketik } \\
\text { nama barang secara } \\
\text { manual } \\
\end{array}$ & $\begin{array}{l}{[\sqrt{ }] \text { diterima }} \\
{[\text { ]ditolak }}\end{array}$ \\
\hline 3. & Employee List & $\begin{array}{l}\text { Mengubah data } \\
\text { User dan Admin }\end{array}$ & $\begin{array}{l}\text { Mengubah data } \\
\text { User atau Admin } \\
\text { yang sudah }\end{array}$ & $\begin{array}{l}\text { [V]diterima } \\
{[\text { ]ditolak }}\end{array}$ \\
\hline
\end{tabular}


Perancangan Aplikasi Sistem Informasi Barang Berbasis Android Pada PT. Quantum Mitra Sinergi

\begin{tabular}{|c|c|c|c|c|}
\hline & & & $\begin{array}{l}\text { tersimpan di dalam } \\
\text { basis data }\end{array}$ & \\
\hline & & $\begin{array}{l}\text { Cari daftar User } \\
\text { atau Admin }\end{array}$ & $\begin{array}{l}\text { Sistem akan } \\
\text { menampilkan daftar } \\
\text { User atau Admin } \\
\text { yang dicari }\end{array}$ & $\begin{array}{l}{[\sqrt{ }] \text { diterima }} \\
{[\text { ]ditolak }}\end{array}$ \\
\hline & & $\begin{array}{l}\text { Ekspor data User } \\
\text { dan Admin }\end{array}$ & $\begin{array}{l}\text { Sistem } \\
\text { mengkonversi data } \\
\text { User atau Admin } \\
\text { yang ada di dalam } \\
\text { basis data ke dalam } \\
\text { format Excel }\end{array}$ & $\begin{array}{l}{[\sqrt{ }] \text { diterima }} \\
{[\text { ]ditolak }}\end{array}$ \\
\hline & & $\begin{array}{l}\text { Menambahkan } \\
\text { User baru }\end{array}$ & $\begin{array}{l}\text { Data pekerja baru } \\
\text { dimasukkan secara } \\
\text { lengkap }\end{array}$ & $\begin{array}{l}{[\sqrt{ }] \text { diterima }} \\
{[\text { ]ditolak }}\end{array}$ \\
\hline 4. & Profile & $\begin{array}{l}\text { Mengubah kata } \\
\text { sandi }\end{array}$ & $\begin{array}{lr}\text { Sandi } & \text { baru } \\
\text { dimasukkan dan } \\
\text { melakukan verifikasi } \\
\text { ulang sandi yang } \\
\text { baru }\end{array}$ & $\begin{array}{l}{[\sqrt{ }] \text { diterima }} \\
{[\text { ]ditolak }}\end{array}$ \\
\hline
\end{tabular}

Tabel 2 Hasil Pengujian pada Aplikasi Mobile

\begin{tabular}{|c|c|c|c|c|}
\hline No. & Form yang diuji & Skenario Uji & Hasil Pengujian & Jenis Pengujian \\
\hline \multirow[t]{2}{*}{1.} & \multirow[t]{2}{*}{ Login } & $\begin{array}{l}\text { Masukkan data } \\
\text { username dan } \\
\text { password yang } \\
\text { benar }\end{array}$ & $\begin{array}{l}\text { Proses login berhasil } \\
\text { dan masuk ke } \\
\text { halaman home }\end{array}$ & $\begin{array}{l}\text { [V]diterima } \\
{[\text { ]ditolak }}\end{array}$ \\
\hline & & $\begin{array}{l}\text { Masukkan data } \\
\text { username dan } \\
\text { password yang } \\
\text { salah }\end{array}$ & $\begin{array}{l}\text { Proses login gagal } \\
\text { atau sistem } \\
\text { menolak }\end{array}$ & $\begin{array}{l}\text { [V]diterima } \\
{[\text { ]ditolak }}\end{array}$ \\
\hline \multirow[t]{2}{*}{2.} & \multirow[t]{2}{*}{ Item List } & $\begin{array}{l}\text { Mencari daftar } \\
\text { barang }\end{array}$ & $\begin{array}{l}\text { Sistem akan } \\
\text { menampilkan daftar } \\
\text { barang yang dicari }\end{array}$ & $\begin{array}{l}\text { [V]diterima } \\
{[\text { ]ditolak }}\end{array}$ \\
\hline & & $\begin{array}{l}\text { Menghapus daftar } \\
\text { barang }\end{array}$ & $\begin{array}{l}\text { Menghapus daftar } \\
\text { barang yang telah } \\
\text { terimpan di dalam } \\
\text { basis data }\end{array}$ & $\begin{array}{l}{[\sqrt{ } \text { ]diterima }} \\
{[\text { ]ditolak }}\end{array}$ \\
\hline \multirow[t]{2}{*}{3.} & \multirow[t]{2}{*}{ Add New } & $\begin{array}{l}\text { Menambahkan } \\
\text { tipe barang baru }\end{array}$ & $\begin{array}{l}\text { Barcode barang di } \\
\text { scan lalu tipe } \\
\text { barang di ketik } \\
\text { secara manual dan } \\
\text { gambar barang di } \\
\text { foto dan } \\
\text { dimasukkan secara } \\
\text { manual }\end{array}$ & $\begin{array}{l}\text { [V]diterima } \\
{[\text { ]ditolak }}\end{array}$ \\
\hline & & $\begin{array}{l}\text { Menambahkan } \\
\text { daftar barang } \\
\text { baru }\end{array}$ & $\begin{array}{l}\text { Barang dengan tipe } \\
\text { yang telah } \\
\text { tersimpan di dalam } \\
\text { basis data di scan } \\
\text { kemudian ketik } \\
\text { nama barang secara } \\
\text { manual }\end{array}$ & $\begin{array}{l}\text { [V]diterima } \\
{[\text { ]ditolak }}\end{array}$ \\
\hline 4. & Profile & $\begin{array}{l}\text { Mengubah kata } \\
\text { sandi }\end{array}$ & $\begin{array}{lr}\text { Sandi } & \text { baru } \\
\text { dimasukkan dan } & \text { dakukan verifikasi } \\
\text { melakuna }\end{array}$ & $\begin{array}{l}\text { [V]diterima } \\
{[\text { ]ditolak }}\end{array}$ \\
\hline
\end{tabular}




\begin{tabular}{|l|l|l|l|}
\hline & & $\begin{array}{l}\text { ulang sandi yang } \\
\text { baru }\end{array}$ & \\
\cline { 3 - 4 } & Mengubah foto & $\begin{array}{l}\text { Pekerja } \\
\text { mengunggah foto } \\
\text { dari album foto atau } \\
\text { dengan mengambil } \\
\text { foto menggunakan } \\
\text { kamera smartphone }\end{array}$ & {$\left[\begin{array}{l}{[\sqrt{ }] \text { diterima }} \\
{[\text { ditolak }}\end{array}\right.$} \\
& & & \\
& & &
\end{tabular}

\section{Kesimpulan dan Saran}

Berdasarkan hasil perancangan sistem inventaris pada PT. Quantum Mitra Sinergi, dapat disimpulkan sebagai berikut:

1. Dengan adanya aplikasi sistem inventaris yang dikembangkan, maka laporan barang keluar dan masuk dari dan ke dalam gudang dapat dikelola di dalam aplikasi yang dikembangkan.

2. Aplikasi sistem inventaris barang pada PT. Quantum Mitra Sinergi berbasis Android dan Web dapat memberikan laporan barang masuk dan keluar dari dan ke dalam gudang penyimpanan ke dalam format Exce/dengan lebih mudah.

3. Aplikasi berbasis Android sistem inventaris pada PT. Quantum Mitra Sinergi dapat melakukan penyimpanan barang ke dalam data inventaris maupun mengeluarkan barang dari dalam data inventaris hanya dengan cara scan barcode barang dengan mengandalkan kamera smartphone saja.

Adapun saran penulis dalam perancangan sistem inventaris PT. Quantum Mitra Sinergi adalah sebagai berikut:

1. Diharapkan agar basis data sistem ini diintegrasikan ke dalam basis data server pada PT. Quantum Mitra Sinergi.

2. Diharapkan aplikasi ini dapat disempurnakan lagi karena dibeberapa percobaan waktu yang dibutuhkan dalam membaca barcode pada barang menggunakan sistem scan barcode pada smartphone ini sedikit lama.

Diharapkan aplikasi dan web ini dapat dikembangkan lagi dan diberi tambahan fitur-fitur agar dapat lebih banyak kegunaannya.

\section{Referensi}

[1] Jogiyanto, Analisis dan Desain Informasi Pendekatan terstruktur Teori dan Praktek Aplikasi, Yogyakarta, 2005.

[2] W. Komputer, Shortcourse Series Pengembangan Aplikasi Database Berbasis javaDB dengan Netbeans, Yogyakarta: Penerbit Andi, 2010.

[3] Fahrisal, Pohan, S., \& Nasution, M. (2018). Perancangan Sistem Inventory Barang Pada UD. Minang Dewi Berbasis Website. Informatika : Jurnal I/miah AMIK Labuhan Batu, 17-23.

[4] I. P. A. P. Yudha, M. Sudarma, and P. A. Mertasana, "PERANCANGAN APLIKASI SISTEM INVENTORY BARANG MENGGUNAKAN BARCODE SCANNER BERBASIS ANDROID," J. SPEKTRUM, vol. 4, no. 2, pp. 72-80, Jan. 2018

[5] Sibero, A. F. K. "Kitab Suci Web Programming." Jakarta. Mediakom. 2012.

[6] Bassil, Y.. A Simulation Model for the Waterfall Software Development Cycle, International Journal of Engineering \& Technology (iJET), vol. 2, no.5, 2012. 